\title{
BEING RESPONSIBLE FOR THE LIFE OF ANOTHER HUMAN BEING
}

\author{
Anna Abelsson \\ Jönköping University, School of Health Sciences, Jönköping, Sweden
}

\begin{abstract}
A common feature of prehospital emergency care are short and fragmentary patient encounters with increased demands for efficient and rapid treatment. Crucial decisions are often made, based on the premise of the ambulance staff's ability to capture the situation instantaneously. The assessment is, therefore, a pre-requisite for decisions about appropriate actions. However, a low exposure to severe trauma cases leads to vulnerability for the ambulance staff, which makes the assessment more difficult. Assessment of severe trauma patients at the scene of accident is difficult and complicated. No trauma scenarios are alike and practical skills, training, and feedback are therefore necessary.
\end{abstract}

KEY WORDS: trauma, ambulance, prehospital, responsibility, team work

Disaster Emerg Med J 2017; 2(4): 164-166

It is $5 \mathrm{am}$ and I am woken up by the beeping noise of the pager. I pull my top over my head as I half walk, half run, along the corridor. It is cold. Peter jumps into the car at the same time as I do. He is 55 years old, an experienced colleague who has been a fire fighter and EMT for 25 years. He has seen and experienced most things. We leave the ambulance station. Peter switches on the blue lights but no sirens, it is too early for that. We do not want to wake people up, just get to the scene of accident as quickly as possible. With no people on the roads it is easier. The call-out we have been assigned is classified as a traffic accident. One car has run off the road, two people are assumed to be in the car. Although we have not been given any details about how seriously injured they might be, I still feel prepared.

I am an ambulance nurse with experience of working at an emergency hospital. My years at the hospital have provided me with a sort of clinical eye that I use when working in the ambulance. At the hospital I learned how to assess patients with diseases and injuries in a safe environment surrounded by others. I had the chance to reflect over symptoms and think about differential diagnosis and alternatives.

In the ambulance, as an ambulance nurse, I am the one who is medically responsible as in Sweden there is no physician present in the vehicle. This entails that prioritisation and decisions are to be made by me. Medical knowledge gained from prehospital education, combined with practical experience, has made it possible for me to consolidate theory in a practical setting. Theory is absorbed by the hands, so to speak. It has also provided a sense of flexibility in the assessment and care of patients. To have a reflective way of thinking makes it possible to care for the patient, and then be able to take a step back and reprioritise when the patient has not responded as expected to the care provided. To be able to reflect on the experience makes it possible to let go of tunnel vision and not get stuck in a thought. This, in turn, makes it possible to process a lot of information at the same time. However, experience also means being able to remain humble and confident when things do not always go according to plan, to accept that sometimes one makes mistakes and dare to say that out loud. 
As we approach the scene we can see black tyre marks on the road. An empty car with the hazard light switched on is located on the side of the road. Through my window I can see a car lying on its roof out on the field. Immediately, I take in the surroundings and the factors that will affect the well-being of the patient. The ability to read the scene of an accident and the force the patient has been exposed to partly derive from medical knowledge from prehospital training, and partly from experience of having witnessed scenes of accidents and patients exposed to trauma previously. Therefore, there is already a pre-understanding of the injuries which the people in the car will have suffered.

A person is moving down there; it is the person who owns the car on the side of the road, the one who made the emergency call. I run down the slope and jump over a small ditch. There was more water in the swampy ground than I initially thought, so both my shoes and my trouser legs get wet as I run across the field. Nothing can distract me now because I am focused on what awaits me. I quickly seek eye contact with the man at the scene. "How are you doing?" I ask. "It has all gone horribly wrong", he almost shouts. He has managed to keep it together for a long time but as we arrive he loses it. I put my bags down and kneel down by the car. Meanwhile I ask: "How many are there?". "There are three", he responds. "But I don't know if anyone is alive. They all look dead". I crawl a little bit on my stomach through the broken window in the back seat of the car. I do not want to get too far inside because the car could collapse at any time. In the back seat a man is hanging upside down in his seatbelt. He is making a gurgling noise as the chest is moving. I hold my hand in front of his face, but there seems to be no air passing in or out of the lungs. It is not possible for me to bring him down on my own.

I try to reach my arms through to the front seat, but the front is so squashed I cannot reach any of them. I manage to get a grip of one of the passengers. He is not hanging upside down which is worrying. The front window is completely squashed and his body is damaged. As I touch him I can feel that his body is too flexible. I grab his head and lift it up, but there is no resistance. His cervical vertebras are probably crushed. Carefully, I put his head back down. It bothers me that his head drops to the side and is positioned in an unnatural position. This is wrong; one should not look grotesque, even when dead. I pull his body towards me so he ends up in a foetal position so that his head is kept in place. That took me 10 seconds, and I actually did not have that extra time. As I pull out of the car Peter has reached the driver. We stand up at the same time. Peter looks at me and says: "He is dead". "Yes" I reply, "This one too, but the one in the back seat is alive". We lie down next to each other and I stick my hands inside the car to attempt to hold his head. He was using the seat belt and that saved him. That is why he is alive and his friends are not.

Then we hear a beautiful sound in the far distance - sirens. I completely understand how people feel when the ambulance finally turns up after what seems to be an eternity. That is what I feel when the fire brigade turns up. My "knights" in the red vehicle. At the same time a second ambulance turns up. 'Very good', I think, 'more help'. I let Peter take over and run up to the fence. The chief fire officer finds me immediately as he steps out of the car. "We need to take the fence down and cut the car open. It is lying on its roof and we have a patient that needs to be extracted quickly". He confirms with a nod and turns around to start delegating orders. The fire fighters are already on the move because they have heard every word I said. Having access to the rescue service is an element of security as it consists of competent staff that work fast and smoothly.

The second ambulance is staffed by Emelie, a registered nurse, and Eva, an experienced ambulance nurse. I know that Eva has experience of dealing with both her own stress and others' stress. It feels safe to work together with an experienced ambulance nurse and it eases the sense of being alone and vulnerable as we run across the field towards the car. Eva thinks in the same way as I do. She has the same medical responsibility and the same knowledge. We work with a long-term perspective and our specialised prehospital knowledge ensures that we know the consequences of the different decisions we make. Moreover, we are able to discuss things together. I say my ideas and thoughts out loud and Eva responds to them. She functions as someone who checks and confirms my choices and actions.

Our care environment requires that we take the whole scenario into consideration, not just the patient. The work on-site must be planned and organised, the remainder of the rescue service staff need to be delegated work and decisions have to be made quickly with too little information to base them 
upon. One must learn to see the whole situation as organised chaos where it is actually possible to keep the strings together. However, that requires specific prehospital training. Working in a hospital means access to a well-lit, warm environment with plenty of colleagues around. Out in the field, wading in cold muddy water, one is much more vulnerable.

At least we had some daylight today, which is nice. It is much more difficult working when it is pitch-black. The fingers do not function $100 \%$ when it gets too cold either, and things take longer to do. Both the patient and I get cold quite quickly in a situation like that. I call out for Peter to fetch a couple of blankets. We cannot just place them on him, instead we have to tie them to his body. Not beautifully done, but it is the best we can do.

When the fire fighters get to the car they ask if they should cut open to entire roof instead so that all three people can be taken out. "No", I respond, "We are prioritizing the man in the back". Being medically responsible entails being in charge at the accident scene and requires the courage to make decisions and stick to them. The firefighters know what needs to be done. They have questioned my decision, but they trust me.

It takes some time to manage to open the car to the point where we can get the injured man out. We have collected the equipment we need already so we are ready to start working as soon as we get access to him. Although we carry quite a lot of material in the vehicle, most of it we do not use that often. That is why it is important that we have been trained on using the material so that when we do find ourselves in a situation where we need to use it, we know what to do. That is also why we also need training on those care actions we rarely perform. To achieve a routine in working with severe trauma is not possible, not by training on real patients anyway. We rarely treat severe trauma patients, but when we do, everything has to be done correctly right from the start. No time must be wasted and no mistakes must be made. Everything has to run perfectly if the patient is to be given the best possible chance of survival. But how am I supposed to know how to do that when not one trauma incident is like the other? If we practiced more perhaps this feeling of insecurity would be reduced. The patient would also receive better and safer care. We should not practice on patients - we should practice before we work in the ambulance with the lives of other people as our responsibility.
We deliver the patient to the accident and emergency department at the hospital. A full trauma team awaits us, 8 people in total; 3 physicians, 4 RNs and 1 staff nurse. In the ambulance we were only 2 ambulance nurses and Peter, who was driving.

I suspect that the patient will not make it through the morning. His body was so damaged that it feels like he cannot possibly survive. It felt like life had already left him when I first met him, but we artificially kept life in him for a little longer. This is when the difficult thoughts come up. As the hospital takes over we are left out. What we need now is to go back to the station, sit down in the kitchen and talk. We need to talk about what happened and what we did. I always do my best, but could I have done my best differently? These are thoughts I deal with every time I have been responsible for another person's life or death. To be able to keep working in the ambulance I need to assess whether my own practice corresponds to that of others. One needs confirmation that the right actions have been taken and that the patient has received the best possible care. Confirmation from the hospital works as a reassurance that no mistakes have been made. One wants to find out what types of injuries the patient had, so that it can be compared with one's own suspicions. If I find that out later, I can learn from that experience. I know the symptoms the patient suffered and I can then learn for next time which treatment will be best. The risk of making mistakes the next time is reduced. Through these conversations I can also deal with what I have been through. It is necessary to regain the strength to carry on.

My shift is finishing and on my way home from work the adrenaline has returned to a somewhat more normal level. I start to sense the feeling of satisfaction in my body. We did all we could have done throughout the whole mission. We cooperated smoothly. The ambulance and the fire brigade delivered throughout. In hindsight, there is nothing we could have done or should have done differently, and that is a good feeling. I will be able to let go of this incident and move on. I have gained experience that reinforces me as an ambulance nurse and as a person. I will bring that experience with me onwards into the future.

Conflict of interest: None declared. 